\title{
ТСM \\ Dimensions of trust in different forms of science communication: the role of information sources and channels used to acquire science knowledge
}

\section{Sonia Brondi, Giuseppe Pellegrini, Peter Guráň, Martin Fero and Andrea Rubin}

\begin{abstract}
This paper investigates the dimensions of trust and the role of information sources and channels in developing differentiated forms of science communication. The discussions from two public consultations carried out in Italy and Slovakia about controversial science-related topics were quali-quantitatively content analysed. The results show that scientific knowledge pervades diverse communication spheres, producing differentiated paths of trust in science. Each path is determined by topics (environment or health-related), information sources and channels preferred, and specific features of the multifaceted notion of trust. The contribution discusses cross-national commonalities and specificities and proposes implications for science communication.
\end{abstract}

Keywords

DOI

Introduction
Public engagement with science and technology; Public perception of science and technology; Science and media

https://doi.org/10.22323/2.20030208

Submitted: 16th November 2020

Accepted: 21st March 2021

Published: 10th May 2021
Over the past twenty years, the scientific community and decision-makers have questioned the level of trust that the public has in science. In some cases, such as the recent Sars-Cov-2 pandemic, there have also been conflicts between politicians and scientists over scientific truths arising from populist attitudes and the spread of false beliefs. Scientific knowledge is not only exposed to the flow of fake news but, according to some authoritative observers, it is also at the centre of a proper attack on science [Achenbach, 2015; Vernon, 2017; Crease, 2019] with tangible threats for millions of people's health or environment protection [Douglas and Sutton, 2015]. Despite these controversies and the intense debate in the media worldwide, various surveys show that public trust in scientific institutions, scientists and the information they transmit is still strong.

The survey carried out in the United States of America by the Pew Research Center in 2016 shows that scientists, among 13 institutions considered, are still the group 
for which the level of trust has remained stable since the Seventies of the last century [Funk and Kennedy, 2020]. The level of trust varies depending on the topics considered; for example, in the case of genetically modified food, the public is quite sceptical of scientists working in agricultural biotechnology and, even more, of leading companies in the agri-food sector.

Similarly, even more clearly on an international scale, other reports have confirmed many positive attitudes towards science. The Wellcome Global Monitor in 2018, which involved over 140,000 people from 140 countries around the world, presented the following results: $72 \%$ of people trust scientists; more than a half $(57 \%)$ of the world's population do not think they know much about scientific issues; $73 \%$ of people trust the opinion of doctors or nurses on health-related topics; these professional figures are considered more reliable than the viewpoint of the family circle, friends, religious leaders or famous people [Wellcome Trust, 2019].

Worldwide, people with lower household income have the least confidence in hospitals and healthcare systems. About vaccines, the Wellcome Global Monitor has recently found that more than three-quarters of the world's population agrees that vaccines are safe and effective $(79 \%$ and $84 \%$, respectively). Considering the regional dimension, useful for the comparison between Italy and Slovakia that is the focus of this study, it is noted that, generally, the level of confidence in vaccine efficacy is higher in southern Europe than in eastern Europe: 70\% versus 65\% [Wellcome Trust, 2019].

The recent Eurobarometer survey on vaccine perception and information sources highlights that offline information is reliable. A significant difference in the level of trust between Italy and Slovakia emerges: in both contexts, the primary information source is the family doctor and the paediatrician, but for $60 \%$ of Slovaks as against $41 \%$ of Italians [European Union, 2019].

The level of trust in science and technology is undoubtedly influenced by communication ecologies and political systems in different national contexts. Notably, media use is a relevant predictor of trust in science, especially for non-conservative news media use, newspapers, and Internet use [Dudo et al., 2010; Hmielowski et al., 2014].

Few studies have examined information sources and channels from a cross-national perspective. This paper fills this gap by investigating the relationship between diverse information sources and channels and public trust in science, comparing two very different countries: Italy and Slovakia, considering some peculiar differences that have been mentioned above.

Italy is a Mediterranean country in southern Europe with 60 million inhabitants and a human development index of 0.892. The most important sectors of Italy's economy in 2018 were wholesale and retail trade, transport, accommodation and food services $(21.4 \%)$, industry $(19.4 \%)$ and public administration, defence, education, human health and social work activities (16.6\%).

Italy is a "television-centred" country, and usually public and private broadcasts are the agenda setters for news and information. In the case of the Covid-19 pandemic, in the spring of 2020, television played a fundamental role and, together 
with the newspapers, it was the most used media for following scientific news on the Covid-19 issue [Bucchi and Saracino, 2020]. In recent years, the diffusion of newspapers and magazines has been dramatically reduced while the Internet's information products have increased. Another media that has great attention is the radio, toward which there is strong confidence [Media Landscape, 2020].

Slovakia is a Continental country in eastern Europe with 5.4 million inhabitants and a human development index of 0.860 . The most important sectors of Slovakia's economy in 2016 were industry $(27.3 \%)$, wholesale and retail trade, transport, accommodation and food services $(21.6 \%)$ and public administration, defence, education, human health and social work activities (13.4\%).

Slovakia is a country where citizens are mainly informed through television considering national political issues. Unlike Italy, the second information channel is the Internet thought the primary information source about national political issues in late 2015 [European Union, 2019]. From a European perspective, Slovakia belongs to a group of countries below the statistical range in both television and newspaper consumption (such as Bulgaria, the Czech Republic, Lithuania and Ukraine). However, the trust in those media channels is higher than the trust in the more often used digital media. According to data from European Value Survey 2017, Slovakia belongs to the countries with the lowest General trust in Europe, except for the family or family members [Mrva, 2019]. However, it is interesting that the family cycle does not play an important role for science communication, and people use various forms of verification through different strategies (e.g., triangulation of information sources).

The debate on the public communication of science is not very lively in Slovakia. Lack of discussion about this topic can be seen in society-wide discussions and public interests, as well as at the level of scientific and professional discourses [Gavurová et al., 2018]. There are no research teams in scientific workplaces that address this topic; moreover, no Slovak universities teach this subject, and, so far, the issue of science communication has not appeared in national grant schemes. Scientific research and its conclusions are usually known only to a limited number of experts. Scientific knowledge is popularised only by a few active and enthusiastic journalists or experts and has no clear strategy and systematic approach.

The comparison between the two countries becomes important considering that, in Italy, there is a more robust tradition of scientific journalism that has developed since the 1950s, there are some very popular television broadcasts, and some masters in science journalism with a lively international perspective are active [Pellegrini and Rubin, 2020].

Thus, we can claim that the H2020 CONCISE$^{1}$ project has carried out a pioneer activity in this area thanks to the public consultations that have made it possible to collect citizens' views in an innovative and unprecedented way. Through these activities, researchers can collect people's reasonable and justified perceptions of reality, considering the complexity of the relationship between their direct observation and scientific knowledge [Scheufele and Krause, 2019]. Different

\footnotetext{
1 "Communication role on perception and beliefs of EU Citizens about Science" - CONCISE project (SwafS, GA n. 824537), coordinated by the University of Valencia (Spain).
} 
people involved have specific values, and "the relationship between changing scientific communities results in an evolving new ecology of science communication that needs to be recognised in all its richness, in order to understand the relationship between the new social media and the mechanisms of fluctuating public trust" [Koivumäki, Koivumäki and Karvonen, 2020, p 426]. Indeed, a wave of studies has begun to explore the effects of various forms of online disinformation, their characteristics and how they affect online social interactions and human thinking [Kahan, 2017] and sought to understand the role of fake news in fueling a climate of mistrust towards science and scientists [Brossard, 2013].

Considering this situation, the CONCISE project has clearly shown people's willingness to share scientific knowledge and their need to verify multiple sources. Nevertheless, the clarity and comprehensibility of this information remain a problem, as does the availability of the information in the mainstream media. The majority of the population trust the statements and opinions of existing professionals and scientific institutions that are mainly state institutes and inspectorates in health, control of food and agricultural products, whether domestic but recently also imported products [European Union, 2019; Wellcome Trust, 2019]. However, there is often none or only a few information from these institutions available.

In the absence of this information, people seek personal contacts with experts in the field. Personal contacts are a widespread source of knowledge, too, and the most frequent scenario is that people pass on the information through family, friends and acquaintances. People less frequently approach colleagues from work, strangers or other professionals outside the immediate family-friendly circle.

Drawing upon these theoretical premises, the present study aims to shed light on the multifaceted notion of trust in science and science communication. Adopting a cross-national perspective, the main objective of the study is to identify the common dimensions underlying the issue of trust and their intertwined role in shaping differentiated forms of science communication. In other words, the guiding questions of this contribution are: how do citizens approach science? And, why do some information sources and channels favour the development of trust while others inhibit this process?

This objective entails specific research questions, which serve both theoretical and methodological interests and have applied implications. The research questions are:

- RQ1: What forms of science communication can be identified?

- RQ2: How do information sources and channels contribute to define differentiated forms of science communication?

- RQ3: How does the issue of trust, in its multifaceted dimensions, enter this picture?

Specifically, on a theoretical level, this study aims to contribute to the lively debate on the issue, emphasising the common features among different cultural 
backgrounds; on a methodological level, it seeks to test participatory and qualitative investigation tools, which are usually less adopted in studies on this research object. Finally, in answering such research questions, this study intends to contribute to enhance the most effective forms of science communication about controversial issues and to improve those that, on the contrary, are perceived as most deficient.

This study, based on Italian and Slovak data, is part of the CONCISE project aimed to understand the role science communication plays on laypeople beliefs and perceptions about scientific issues. CONCISE organised public consultations in five European countries (three from the Mediterranean area, i.e. Italy, Portugal and Spain, and two from the Eastern area, i.e. Poland and Slovakia) about four science-related controversial topics (i.e. climate change, vaccines, genetically modified organisms - GMOs, and complementary and alternative medicines CAMs). The choice of limiting the comparison to two countries is motivated by the method used: studying different cases. According to this method - as already indicated by some seminal works on comparative studies [Lijphart, 1971; Seawright and Gerring, 2008] - , areas, different populations, diverse communication traditions and public discourses on science and technology are all essential variables that raise fruitful reflections on the trust paths taken by citizens to acquire information. Using a mixed-method approach (integrating quantitative and qualitative methods) made it possible to balance internal and external validity; the two countries, i.e. Italy and Slovakia, were the most suitable for studying different cases within CONCISE [Prescott and Urlacher, 2017].

\section{Materials and participants}

The Italian public consultation (Vicenza, September 14, 2019) involved 93 citizens from 37 municipalities; the Slovak public consultation (Trnava, October 19, 2019) involved 99 citizens from 37 localities. As shown in Table 1, the participants of both consultations were selected following the representativeness of the population according to four socio-demographic characteristics: gender, age group, educational level [ISCED, 2013] and residence [Eurostat, 2019].

The public consultations, both in Italy and Slovakia, were structured as follows: first, the citizens were randomly assigned to ten discussion tables; then, they participated in scheduled one-hour discussions about each of the four science-related topics under investigation. A facilitator guided every table with the support of an observer, both trained for that task. The facilitators adhered to a shared script, which planned to address three main areas: how citizens are informed, how reliable the information sources are, how to improve science communication. This study focuses specifically on the first two aspects, as well as on their mutual relationships.

\section{Procedure and analysis}

The discussions at the ten tables were audio-recorded, producing about 80 hours of recording in each public consultation. They were processed, entirely transcribed and made anonymous to protect the participants' privacy. 
Table 1. Italian and Slovak citizens involved in public consultations by socio-demographic characteristics.

\begin{tabular}{|cccc|}
\hline & & Italy & Slovakia \\
\hline \multirow{7}{*}{ Gender } & Male & 50 & 42 \\
& Female & 43 & 57 \\
\cline { 2 - 4 } & $\leq 24$ & 15 & 18 \\
& $25-34$ & 14 & 31 \\
& $35-44$ & 23 & 16 \\
& $45-54$ & 17 & 17 \\
& $55-64$ & 15 & 10 \\
& $\geq 65$ & 9 & 7 \\
\hline \multirow{4}{*}{ Educational level } & Primary & 16 & 3 \\
& Secondary & 35 & 40 \\
& University & 42 & 56 \\
\hline \multirow{2}{*}{ Residence } & Urban & 67 & 66 \\
& Rural & 26 & 33 \\
\hline
\end{tabular}

The transcriptions were submitted to different forms of content analysis.

First, lexical-metric analyses with the aid of the T-Lab software were run.

Operationally, the corpus was built collecting all the transcriptions into a single file, deleting the facilitators' words and associating each conversational turn with the corresponding participant's socio-demographic characteristics. Then, the corpus was imported, and the vocabulary was automatically created, omitting stop-words and lemmatising the retained lexical forms. Finally, the words with ten or more occurrences (i.e. keywords) were submitted to a thematic analysis of elementary contexts. Figure 1 and Table 2 summarised some information about the Italian and Slovak textual corpora.

Figure 1. Italian (left side) and Slovak (right side) word cloud: Most frequent keywords (the first 100).
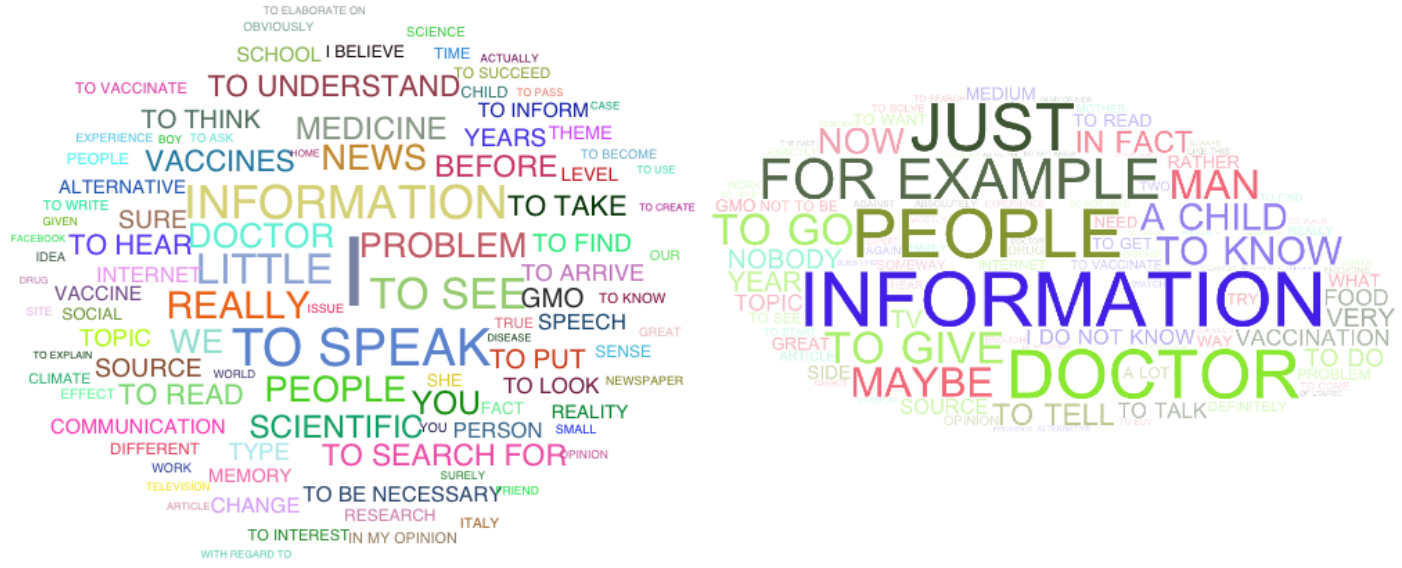

Thematic analysis of elementary contexts allows for a synthesis of the corpus contents performing both cluster analysis and lexical correspondence analysis. Cluster analysis identifies shared core themes; each thematic cluster consists of a set of elementary contexts (i.e. short text portions characterised by the same patterns of keywords) and is described by co-occurring keywords and variables' 
Table 2. Italian and Slovak corpora: Textual statistics.

\begin{tabular}{|ccc|}
\hline & Italy & Slovakia \\
\hline Number of conversational turns & 4,797 & 3,528 \\
Number of total occurrences (Tokens) & 209,213 & 107,455 \\
Number of distinct forms (Types) & 13,998 & 16,414 \\
Number of single-occurrence types (Hapaxes) & 6,695 & 8,918 \\
Types/Tokens ratio & 0.067 & 0.153 \\
Hapaxes/Types ratio & 0.478 & 0.543 \\
Number of keywords ( $\geq 10$ occurrence types) & 1,275 & 1,059 \\
Number of elementary contexts & 6,421 & 4,119 \\
\hline
\end{tabular}

modalities. Lexical correspondence analysis projects keywords, thematic clusters and variables' modalities into a multifactorial space defined by bipolar dimensions, which can be semantically interpreted. Observing the positioning and the mutual proximity or distance of the elements within the space, overall considerations of the corpus can be advanced.

Second, qualitative analyses with the support of the NVivo software were carried out to complement and corroborate previous results. Thus, it should be noted that each outcome presented below is the result of the joint interpretation of insights that emerged from the triangulation of the two analyses taken together.

Operationally, a preliminary coding scheme, based on the three areas of the discussion script, was developed. Then, it was populated during the coding process with relevant nodes emerging bottom-up from the corpus. Specifically, to achieve the aim of the study, the following aspects and their mutual relationships were examined (Table 3):

a. sources and channels used to acquire scientific information, where sources correspond to the senders of information and channels correspond to how information is transferred from sources to recipients;

b. trust vs mistrust toward science communication, that is, at what level the expectations of the recipients on the scientific information is placed;

c. features of trust in science communication, and specifically 'authority', i.e. the quality of the information sources (e.g., competence, scientific evidence, authoritativeness, data, referenced information, factual information), and 'credibility', i.e. the accuracy of the messages conveyed (e.g., adequate language, explanations, completeness, independence, in-depth contents). Each aspect was investigated as a whole and depending on the topic discussed.

\section{Results}

\section{Information sources and channels}

As shown in Table 3, media are the most widely used information channels, with a slight preference for traditional media in Italy and digital ones in Slovakia. Among 
Table 3. Italian and Slovak code trees: Main coding references. Note. The numbers indicate the number of conversational turns coded with that node (i.e. coding references).

\begin{tabular}{|cccc|}
\hline & & Italy & Slovakia \\
\hline & $\begin{array}{c}\text { Citizens } \\
\text { (e.g., family circle, friends, colleagues, teachers, } \\
\text { students, acquaintances, strangers) }\end{array}$ & 227 & 283 \\
& Communicators & 225 & 516 \\
& (e.g., experts, journalists, opinion leaders) & & \\
& Digital media & 434 & 541 \\
Channels/sources & (e.g., blogs, Internet, social networks) & 117 & 181 \\
of information & Institutions & 89 & 151 \\
& Organisations & 49 & 22 \\
& (e.g., civil society, companies, governmental) & & \\
& Politicians & 271 & 134 \\
& Personal experience & 255 & 78 \\
& (e.g., education, everyday life, work) & 478 & 340 \\
& Scientists & 278 & 279 \\
\hline Trust/mistrust & Traditional media & 227 & 232 \\
\hline continuum & Trust & 200 & 248 \\
\hline Features & Mistrust & 94 & 155 \\
\hline of trust & Authority & & \\
\hline
\end{tabular}

the traditional media, television is by far the most cited, with numerous references to newscasts and documentaries and specific TV channels (also international) or TV shows. Then, newspapers (mainly national, but also local or international), especially in Italy, and magazines and books (including school or university textbooks), especially in Slovakia, follow. Scientific journals and radio have less relevance, even if mentioned. Among digital media, the Internet (and, in particular, specialised or generalist websites, forums and, more generally, the Google search engine) is the most primarily evoked channel, followed by social networks and, to a much lesser extent, blogs. Instant messaging applications and e-mails have less importance.

Alongside the media, interpersonal exchanges contribute to the acquisition of knowledge about scientific issues. Such exchanges are mentioned in terms of personal experiences, both at school/university or work. They are also cited as by word of mouth, which remains a means to share points of view, opinions and advice on controversial topics such as those under investigation. In addition to personal experiences, direct communication also plays an important role: the participants in the public consultation often evoke friends and family circle as principal information channels or sources, even if references to acquaintances, colleagues, teachers or students and, even, to strangers are present.

Then, in Italy, scientists have a strong influence, especially concerning the health area (e.g., general practitioners, medical specialists, paediatricians, pharmacists); in Slovakia, communicators (i.e. opinion leaders, but also experts or journalists) are frequently cited. Institutional sources, on the other hand, are less indicated: among 
them, the Ministry of Health and universities or research institutes stand out. Similarly, governmental or non-governmental organisations and companies are little used as information channels or sources, remaining relatively marginal throughout the full public consultation. Finally, politicians receive little attention and their voices are hardly considered for information on scientific issues.

The quantitative and qualitative analyses of the discussions collected during the public consultations also highlighted that overall trust perceptions prevail over mistrust considerations and mainly depend on the features of the authority of the sources and credibility of the messages conveyed.

The combined study of the sources and channels associated with the levels of trust in science communication has allowed for the identification of the main forms of communication permeated by scientific knowledge and are described in the following section.

\section{Forms of science communication}

The cluster analysis identified some core themes, which can be interpreted as corresponding forms of communication permeated by scientific knowledge, some of which are common to Italy and Slovakia (Table 4). Each thematic cluster is more or less explicitly - defined by keywords referable to information sources and channels as well as to the trust domain, providing initial insights into their role in shaping differentiated forms of science communication.

Table 4. Italian and Slovak thematic clusters. Note. The numbers indicate the number of elementary contexts included in that cluster.

\begin{tabular}{|ccc|}
\hline & Italy & Slovakia \\
\hline Everyday communication & 1,842 & 735 \\
Public communication & 1,190 & 428 \\
Medical communication & 1,137 & 650 \\
Institutional communication & 1,067 & - \\
Expert communication & - & 438 \\
\hline
\end{tabular}

The first thematic cluster, which is the most relevant in both the Italian and Slovak public consultations, frames scientific knowledge within the field of 'everyday communication'.

It does not define reliability in specific terms (e.g., reliable, to trust, to entrust, entrusting), but makes many references to personal experience (e.g., experience, by experience). In this process, interpersonal exchange with family members (e.g., relative, sister, partner, nephew), friends (e.g., friend, acquaintance), colleagues (e.g., colleague) or people considered more experienced (e.g., homoeopath, doctor), to whom relying on their opinion (e.g., to advise, to confront, advice), play an essential role. Traditional (e.g., television, TV, broadcast, program, documentary, newscast, newspaper, article, page, headline, magazine, interview, radio, book, textbook, movie, cinema) and digital (e.g., Internet, Google, online, site, blog, social, network, Facebook, YouTube, WhatsApp, mobile) media are also of great importance. On the one side, the role assumed by personal experience is driving individual choices (e.g., to_come, to_go, 
to_do, to_want); on the other side, the role assumed by the media is entertaining and stimulating curiosity (e.g., pleasure, interest).

The acquisition and interpretation of information rest on the citizen's responsibility (e.g., to_read, to_watch, to_see, to_search, to_listen, to_follow), who autonomously judges the reliability (e.g., fake, news, reliable) and decides whether to share it or not (e.g., to_share, to_write, to_speak, to_publish).

To evaluate the reliability of these multiple information channels/sources, people mainly adopt personal criteria: the deepening (e.g., to_search, to_inform, to_follow, to_deepen, informed, thorough, deepening), the verification (e.g., to_verify, source, author) and the selection (to_evaluate, to_filter).

Finally, there are a few references to reliability in terms of the purpose of communication, which — in this case - is arousing curiosity (e.g., to_interest, interested), to which is sometimes added an 'entertainment' component (e.g., pleasure). Moreover, a few references to reliability in terms of newness (e.g., recent) of the content addressed are also present. The main criticality detected regarding the quality of the information conveyed concerns the risk of the unreliability of the information source or the contents addressed (e.g., fake, mistake, charlatan, rubbish). In this regard, personal experiences are generally considered valuable and trustworthy.

This cluster is mainly associated with the topic of CAMs.

\begin{abstract}
"I'm interested in it because I'm a shiatsu practitioner, so, as a hobby, I started following a type of Chinese medicine in the last two or three years, and I'm interested in all alternative medicines. I visit websites, read books and books, and go to seminars. When I read something on the websites, many times I get pissed off because I see fake news." (Italy, CAMs, female, 55-64, secondary, urban)
\end{abstract}

\begin{abstract}
"In most cases, the news comes to me from people I know: relatives who use various methods or even friends... actually a friend. A friend of mine is a naturopath, the sister of another friend of mine has attended courses, so I always get this news; some are a little more respectable than others..." (Italy, CAMs, female, 25-34, university, urban)
\end{abstract}

\begin{abstract}
"When we hear something in the mass media or on television, I consider it as credible if it is supported by some research or some scientists who are experts and they work in the field for many years. I trust the information from them as I see them as credible and based in science." (Slovakia, GMOs, female, 55-64, university education, rural)
\end{abstract}

The second thematic cluster, which is more relevant in the Italian public consultation than in the Slovak one, frames scientific knowledge within the field of 'public communication'.

It defines reliability mainly in terms of authority of the information sources. Specifically, the sources considered authoritative are the experts (e.g., scientist, 
teacher, researcher, professor, doctoral_student, anthropologist, Nobel), especially if they come from the educational (e.g., school) and academic (e.g., university, faculty, research) context. Moreover, albeit to a lesser extent, the political institutions (e.g., politician, minister, institution) are also mentioned. While media are mentioned (e.g., article, Internet), the main channels through which the communication process is activated are those which provide for direct interactions with such authoritative figures (e.g., seminar, congress) and which allow a certain degree of reciprocity (e.g., debate, discussion, speech, to_debate, to_discuss, to_speak). The role assumed by the public (e.g., our, us, we) is thus to actively contribute to developing a scientific discourse together with the other parts involved, such as politics (e.g., politics), science (e.g., science, scientific) and education (e.g., school, university).

This process, rooted in the acquisition and transmission of information (e.g., dissemination, interest, issue, topic), is dynamic and has effects (e.g., impact) not only in the present, "here-and-now", but also on very differing scales (e.g., years, years_ago,community, union, European, north, country). Active participation implies to have a great responsibility. It outlines the reliability also in terms of the credibility of the messages conveyed, which, on the one hand, should be based on scientific evidence (e.g., data, objective), and, on the other hand, should be adequately communicated (e.g., careful, responsible).

Lastly, there are a few references to reliability both in terms of the purpose of the communication, which - in this case - is the dissemination of science (e.g., dissemination, science, scientific), to which is sometimes added a 'didactic' component (to_learn, to_teach, to_be_aware, to_raise_awareness); and in terms of legitimacy and newness for the relevance (e.g., important, importance, relevant) and the novelty (e.g., new, topical) of the contents addressed. The main criticality detected regarding the quality of the information conveyed concerns the risk of polarisation of the debate. It can lead to alarmism (e.g., alarmism) on the one side, or denialism (e.g., denialist) on the other, as well as to an increase in tones (e.g., controversial). Another criticality also concerns the quantity of the information conveyed. It is perceived as lacking and poorly addressed at the local level, both on the media and institutional sides.

This cluster is associated with environmental topics, especially GMOs in the Italian public consultation and climate change in the Slovak public consultation.

\begin{abstract}
"Speaking of GMOs, in Turin there is a cultural initiative called
'Thursdayscience', where scientific journalists, who have some competences, and scientists (or professionals in specific fields of the weekly topics) propose certain topics in a space open to the public. So, there is the mediator, who is the communicator of science, there is the specialist, the professional, and a specific issue is told to the public. The topic of GMOs was also dealt with there, and Dario Bressanini himself came." (Italy, GMOs, female, 45-54, university, urban)
\end{abstract}

"By chance, presenting books, I met this entomologist [...], and from there we started talking about GMOs, and we had an interesting public debate [...] so what I know is the result of this meeting." (Italy, GMOs, female, 35-44, secondary, urban)

"Young people should be motivated to change their interest to be aware of environment... everyone should draw information from scientific sources 
because they are trustworthy. The scientific community should be the authority as they present the information based on research and statistics." (Slovakia, climate change, female, 18-24, secondary education, urban)

The third thematic cluster, which is common to both the Italian and Slovak public consultations, frames scientific knowledge within the field of 'health communication'.

It defines reliability mainly in terms of the credibility of the messages conveyed. Specifically, the message deemed reliable refers to an idea of 'exact science' and is based on accurate data and scientific evidence (e.g., correct, exact, true, certain, percentage, precise). It delineates the reliability also in terms of authority of the information sources, i.e. the experts (e.g., doctor, pharmacist, physician, paediatrician), considered competent (e.g., competence, competent, to_study). The channels through which the communication process is activated are those that provide for direct interaction with these authoritative figures (e.g., to_explain, to_ask, to_tell, to_call, to_address), which provide the information necessary to understand and evaluate (e.g., to_understand, to_think, to_decide, to_believe) complex (e.g., difficult, complicated) and controversial (e.g., doubt, under_discussion, to_deny, opposite, extreme) issues. The role assumed by physicians is that of providing knowledge about 'hot' scientific issues.

The acquisition and interpretation of information rest on the citizen's responsibility, who, however, are in a passive position, as they are mere recipients of such information process; then, they are left alone in their autonomous elaboration of a personal opinion.

Finally, there are a few references to reliability both in terms of legitimacy to have reassurances about health concerns (e.g., anxiety, fear); and in terms of the purpose of the communication, which - in this case - is the transmission of information (e.g., to_explain, to_tell), to which is sometimes added an attempt to convince (e.g., to_incentivize, to_convince, conviction). The main criticality detected regarding the quality of the information conveyed concerns the doubt about the truthfulness of the contents addressed (e.g., doubt, legend, sceptic, science_fiction), as well as the consequent difficulty in discerning between potentiality (e.g., benefit) and uncertainty (e.g., risk, danger).

As expected, this cluster is associated with health topics, especially vaccines in the Slovak public consultation.

"I think the doctor is the most striking example: I trust my doctor, so I follow him... but it is also a question of faith: you trust a person because he convinces you, then it is certainly not that there is always $100 \%$... a margin of uncertainty there it must be." (Italy, vaccines, male, 35-44, primary, urban)

\footnotetext{
"Being a general practitioner, there is a relationship of trust. He started talking to me trying to make me understand... he isn't the vaccine expert, but obviously - he knows things that I don't know... and he explained the advantages and benefits [of vaccines], why they are done and also the differences between types of vaccines." (Italy, vaccines, male, 25-34, secondary, urban)
} 


\begin{abstract}
"We have a Minister of Health who is from the field, and she knows the topic well; she was talking about vaccination and presented the facts. She explained the benefits and risks of vaccination from the medical point of view, and it was excellent. It was about a ten-minute speech in the national council, very factual and accurate, and I think she said everything that was needed to say. The video was spread and shared through social media." (Slovakia, vaccines, male, $35-44$, university education, urban)
\end{abstract}

The following thematic cluster is specific to the Italian public consultation; it frames scientific knowledge within the field of 'institutional communication'.

It defines 'negative' reliability (i.e. mistrust). Specifically, the sources/channels to which is recognised only marginally authority (e.g., authoritative, capable) are the political institutions (e.g., ministry, politician, minister, government, politics, ministerial), but also - albeit to a lesser extent - the experts (e.g., scientist, agronomist, technician). The channels through which the communication process is activated are those which provide for a 'top-down' transmission of information (e.g., campaign, press_release, policy, regulation, initiative) and in which citizens, as a whole (e.g., citizenship, people, citizen, Italian, society, public), are mere recipients (e.g., to_receive, to_acquire). The role assumed by institutions is to providing information to citizens (e.g., citizenship, to_convey, instruction, to_disseminate) through proper strategies (e.g., tool, coverage, informative).

This process, differently from what the cluster on 'public communication' illustrated, sees citizens in a passive position; this has an impact (e.g., implication, consequence) on the public's acceptance of the decision taken 'from above' regarding the scientific issues (e.g., safeguard, to_generate, alarmism, problem, mistake) and the economic turnouts involved (e.g., company, economic). The passive role of the public is particularly highlighted by the purpose of the communication, which - in this case - is the transmission of the message (e.g., information, to_address, to_supply, to_disseminate, to_transmit, to_distribute, to_spread, disseminating), to which are sometimes added an attempt to orientate thought (e.g., oriented, to_orient) and a 'didactic' component (e.g., training, educational).

The criticalities detected are manifold. On the one hand, they concern the quantity of information conveyed, perceived as deficient (e.g., lack, reduced, to_miss, to_limit) or excessive (e.g., excess). On the other hand, they concern the quality of the information conveyed, assessed as incorrect (e.g., misinformation, wrong), partial (e.g., simplification, to_simplify), poorly communicated (e.g., alarmism, panic, alarmist) or polarised (e.g., partisan, control, monopoly). This latter aspect is supported by recognising the intertwining with the multiple economic implications involved (e.g., company, Bayer, financier, business). The criticalities are 'positively' defined in some further considerations. Some references concern reliability in terms of the credibility of the contents addressed, which should be qualitatively adequate (e.g., valid, quality, effective), that is, based on data and scientific evidence (e.g., true, right, correct, statistical, statistics), complete (e.g., complete), well communicated (e.g., simple, ease, accessible, easy, language) and — above all — independent (e.g., ethical, conscience, sensitivity, responsibility, honest, conscious, neutrality, attention). Other references concern reliability in terms of legitimacy to respond to citizens' expectations and needs (e.g., safeguarding, necessity, right, expectation). 
This cluster is associated with the topic of vaccines, which in Italy is still quite controversial.

It is not unexpected that this thematic cluster is exclusive to Italy because, traditionally, there is widespread mistrust in the political institutions and, consequently, in what they communicate [Bucchi and Saracino, 2019].

\begin{abstract}
"I make them [the vaccines] because they are required by law, but to say that I would put my hand on the fire that the Ministry of Health has a clear conscience to make us necessarily do all these vaccines no... there is an information problem, and - even before of information - there is a reliability problem." (Italy, vaccines, female, 35-44, university, urban)
\end{abstract}

\begin{abstract}
"I see this great thing [the issue of vaccines] falling on me, and I see it as something that is very standoffish, boring. Now they're talking about this because they need it for the elections. After all, the one is from the Democratic party because the other is on Berlusconi's side. You always see it as something they're doing for another reason. The information doesn't seem to an end in itself but always seems to be conveyed by something else. So, basically, it's an issue of trust, because you know that today they talk about this and make it a big scandal, then two years pass and they will never talk about it again as it never existed." (Italy, vaccines, male, 25-34, secondary, urban)
\end{abstract}

The last thematic cluster is specific to the Slovak consultation; it frames scientific knowledge within the field of 'expert communication'.

It defines reliability mainly in terms of availability of the information about science-related topics. On the one hand, the respondents confirm the importance of expert communicators (e.g., doctor, healer) since they are considered as those who have the authority and credibility to talk about discussed topics; on the other hand, they cannot find enough relevant and reliable information about such topics. Expert communicators are considered as those who have the authority and credibility to talk about science. The role assumed by expert communicators is seen as insufficient since the participants miss the clear and visible scientific information in the country (e.g., Slovakia). Respondents assume that the role of expert communicators is necessary for these topics (e.g., scientific, science), but they miss enough accessible, clear and understandable information (e.g., lacking) to analyse in-depth the space between trust and mistrust. The scientific information is replaced by personal experience (e.g., personally) from citizen's (e.g., friend, acquaintance) who share information with participants to elaborate a personal opinion.

The main criticality detected regarding the quality of the information is the truthfulness of some communicators who present themselves as experts (e.g., scepticism). The main criticality is connected with insufficient public access to information from expert communicators, and there is no clear information about them (e.g., benefit, risk).

This cluster is associated with the topics of CAMs and GMOs. 
It is not unexpected that this cluster is exclusive to Slovakia because the results regarding the information sources show that communicators play an essential role in acquiring scientific knowledge.

\begin{abstract}
"In this topic, there is a need for substantiated and scientific information that we can search for more easily. There is not enough clear information, especially scientific, about the benefits are risks that GMO can bring to us." (Slovakia, GMOs, female, 55-65, university education, rural)
\end{abstract}

"I am definitely for scientific evidence of alternative medicine. We can personally have good experience with alternative medicine, but when there is evidence of science that support some kind of alternative medicine which is good for some health problem than people would not be so sceptical about it." (Slovakia, CAMs, male, 35-44, university education, rural)

\title{
Dimensions of trust
}

The subsequent lexical correspondence analysis identified some semantic dimensions, which can be interpreted as corresponding organising principles underlying the issue of trust in science communication and its many facets described above.

The first semantic dimension is expressed along the 'private-public' continuum. The 'private' side incorporates words related to the idea of an information acquisition process for purely personal use; conversely, the 'public' side is composed of words that evoke a form of science communication based on exchange and dialogue. Everyday and medical communications, and the topic of CAMs, stand on the 'private' side; public and institutional communications, and the topics of climate change, vaccines and GMOs, stand on the "public" side stands.

The second semantic dimension is expressed along the 'passive-active' continuum. The 'passive' side is constituted by words that recall a top-down form of science communication, which sees citizens as excluded and loaded with fear and doubt; on the contrary, the 'active' side incorporates words that evoke the idea of a more inclusive process of acquiring and appropriating information, in which citizens interpret and transmit messages. Medical and institutional communications, and the health issues (i.e. the topics of vaccines and CAMs), stand on the 'passive' side; everyday and public communications, and the environmental issues (i.e. the topics of climate change and GMOs), stand on the 'active' side.

The third semantic dimension is expressed along the 'direct-mediated' continuum. The 'direct' side is composed of words that refer to the idea of acquiring information based on the interpersonal relationship; conversely, the 'mediated' side is articulated around words that evoke a form of science communication proposed by media or by institutions. Public and medical communications, and the topics of GMOs and CAMs, stand on the 'direct' side; everyday and institutional communications and the topics of climate change and vaccines stand on the 'mediated' side. 
These three continuums are common to the Italian and Slovak public consultation; two further semantic dimensions are specific to the Slovak consultation. They are the 'lay-expert' continuum and the 'theoretical-practical' continuum.

In Figure 2, Figure 3 and Figure 4, the thematic clusters common to Italy and Slovakia are related to their positioning on the three semantic dimensions (polarities in darker grey), and on the superordinate 'trust-mistrust' continuum; moreover, the reciprocal relationships with preferential information sources and channels, as well as with the features related to reliability of science communication, are shown.

Figure 2. Dimensions of trust in science, based on 'everyday communication'.

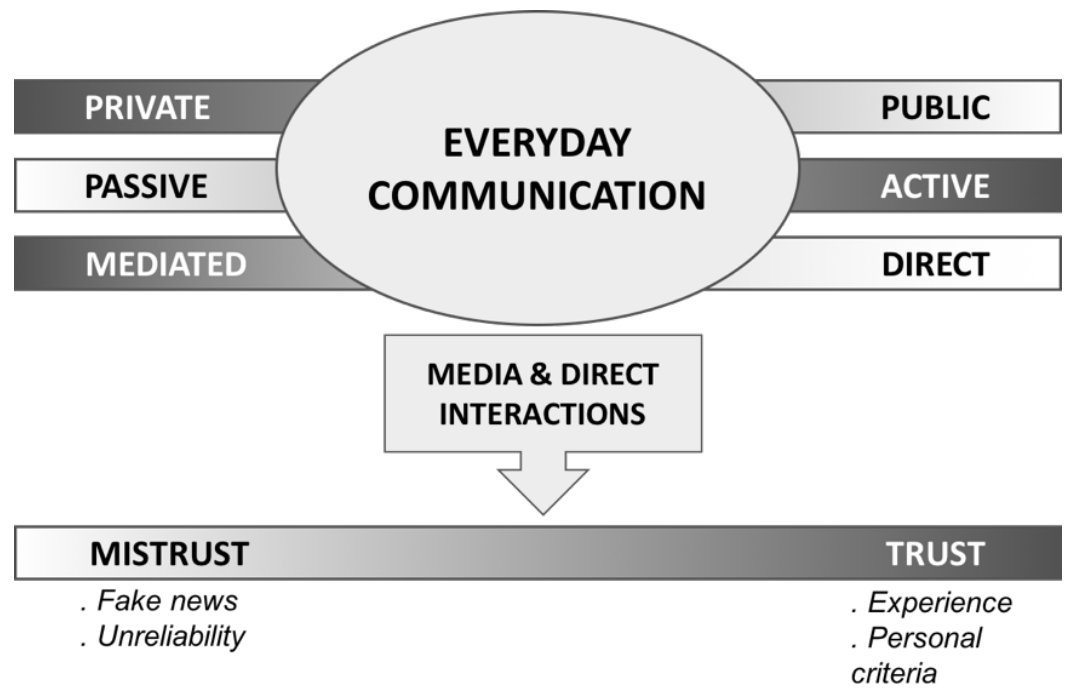

Figure 3. Dimensions of trust in science, based on 'public communication'.

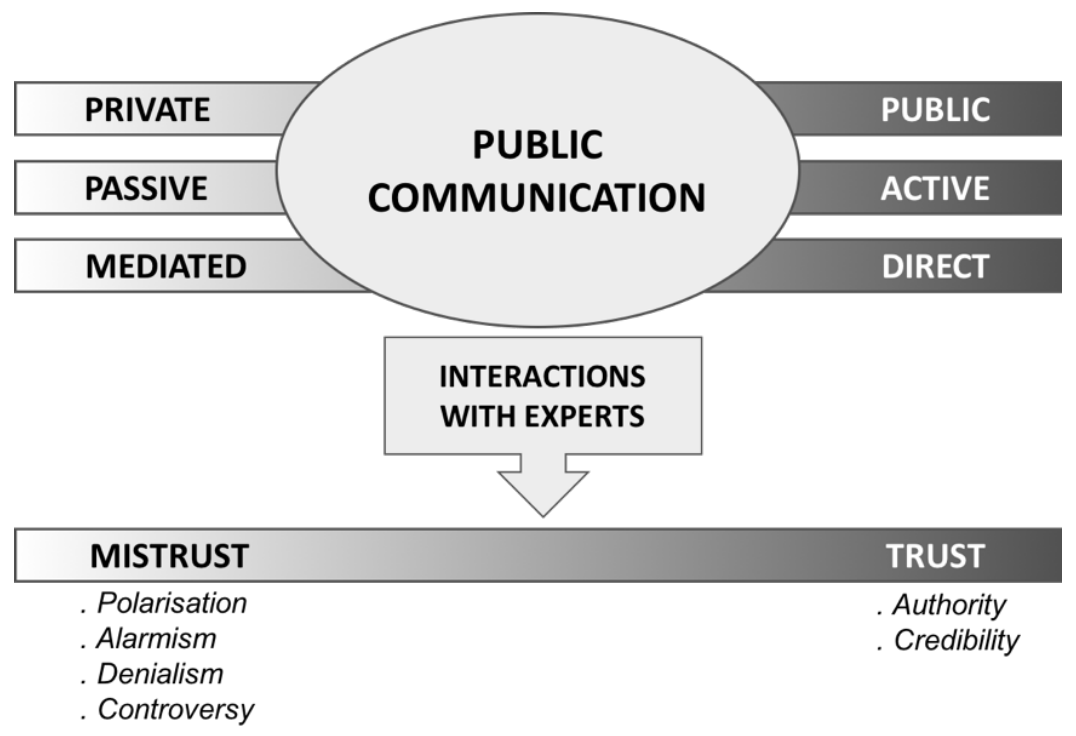


Figure 4. Dimensions of trust in science, based on 'health communication'.

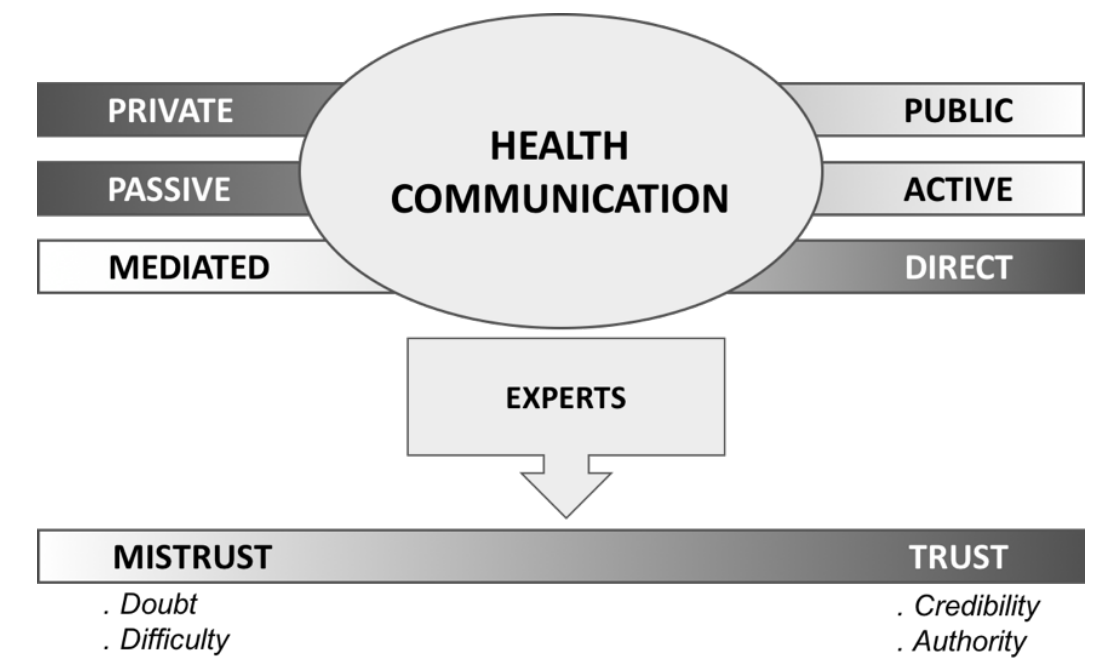

The study aimed to identify the common dimensions of trust in science and science communication and investigate how the information sources and channels used to acquire scientific knowledge play a role in developing differentiated forms of science communication.

Taking a cross-national perspective, the participatory methodology of the public consultation was adopted, and two public consultations involving almost two hundred citizens in Italy and Slovakia about science-related controversial topics were carried out.

Overall, the results emerged from both lexical-metric and qualitative analyses allow for replying to the research questions.

Scientific knowledge is not one and the same but pervades different spheres of communication in the same way that science pervades different daily life spheres. Some of these spheres concern both the Italian and Slovak contexts: everyday communication, public communication, health communication; others concern the Italian context exclusively: institutional communication; still others concern the Slovak context exclusively: expert communication. The incorporation of scientific knowledge within one or another form of communication is characterised by multiple aspects. First of all, the scientific topic under discussion, or the area to which it refers (for example, health or environment). However, these forms of science communication are also characterised by specific channels and preferred information sources, even though both traditional and digital media and interpersonal exchanges are present in a transversal way in all forms, with greater or lesser impact. Furthermore, each form refers to a distinct feature of trust in science communication and reliability of the information sources and channels used: among these, the authority, that is the quality of the information source or channel, and credibility, that is, the accuracy of the message conveyed, play an essential role in defining and delineating the issue of trust and in declining it differently in each form.

These dimensions of trust reflect the cultural, geographical and historical specificities of the context in which they develop, nevertheless highlighting 
commonalities that seem to be superordinate to the context. Furthermore, each form of science communication is initiated and favoured by people who share some socio-demographic characteristics. Some forms are more supported by the younger than the older people or those with a higher level of education than those with a lower one. It should be noted that in this process of differentiation, gender and residence (small or large centres) do not have a significant weight.

Overall, some dimensions underlying how each forms is articulated with respect to the issue of trust can be found both in the Italian and Slovak contexts: mediated-direct, public-private, active-passive, theoretical-practical and expert-lay.

The first mediated-direct dimension highlights how traditional media (TV and press) are still the channels from which information sources are drawn, especially when citizens want to explore a topic of interest. However, the relational modalities, which, especially in the case of health, represent important information sources and discussion, should not be underestimated. Family and friend circles are confrontation and exchange areas in which opinions, attitudes, and critical visions towards science and technology are formed.

The public-private dimension makes it possible to identify the role recognised by institutional and expert sources in the scientific debate, but, at the same time, the importance attributed to personal experience in incorporating this knowledge into the daily practice of the private sphere.

Finally, the active-passive dimension emphasises the contribution of citizens in the co-construction of techno-scientific issues. On the one hand, channels that imply direct interactions with peers or experts are evoked, but also the desire to inform and learn more through traditional or digital media denotes a certain degree of interest and involvement of individuals; on the other hand, methods of communication from above by institutions and scientists leave citizens in a decentralised position with respect to the scientific debate.

Given the complexity of the issues and aspects considered, it should be considered that, taken individually, these dimensions cannot explain the levels of trust or distrust, nor can it be assumed that some polarities of these dimensions 'universally' favour or hinder the development of trust in science and science communication. In the mutual combination of these dimensions and their emerging polarities, it is possible to detect different orientations.

The results outlined so far should be read to enhance more effective forms of science communication. Specifically, they show that trust is not fuelled primarily by the media; rather, especially about issues relating to health, trust in science and technology develops thanks to interpersonal relationships and belonging to certain social circles. Also, specific forms of science communication should be envisaged to meet the needs of different population groups, such as those defined by age and educational level.

In summary, careful consideration of this complexity of factors can allow the different actors involved in the public communication of science to activate effective paths of trust, knowing that different paths may produce different effects. 
To conclude, the public consultation, in addition to providing information on the perception and degree of knowledge of citizens about controversial scientific issues in line with what has already been suggested by the literature and statistics existing at the national and international level, offered interesting insights. The very nature of the methodology used, which provided for the active participation of citizens, had a double advantage: on the one hand, it made it possible to qualitatively detect the point of view of non-experts in dialogue with each other and to listen to their proposals for improvement in order to include them in concrete recommendations to be submitted to the attention of scientists and other involved figures, including science communicators and policymakers, who increasingly find obstacles in the tortuous attempt to communicate science successfully; on the other hand, this qualitative and participatory methodology has activated the involvement of citizens in the processes of scientific research, favouring, in a generative and productive way, the desired approach to responsible and inclusive research and innovation.

\section{References}

Achenbach, J. (March 2015). 'Why Do Many Reasonable People Doubt Science?' National Geographic.

Brossard, D. (2013). 'New media landscapes and the science information consumer'. Proceedings of the National Academy of Sciences 110 (Supplement 3), pp. 14096-14101. https://doi.org/10.1073/pnas.1212744110. PMID: 23940316.

Bucchi, M. and Saracino, B. (2019). 'Scienza, tecnologia e opinione pubblica in Italia nel 2018'. In: Annuario Scienza Tecnologia e Società. Ed. by G. Pellegrini and B. Saracino. Bologna, Italy: Il Mulino.

- (19th April 2020). 'Italian citizens and COVID-19: one month later - April 2020'. Public Understanding of Science Blog. URL: https : / / sagepus . blogspot . com /2020/04/italian-citizens-and-covid-19-one-month.html.

Crease, R. P. (2019). 'The rise and fall of scientific authority - and how to bring it back'. Nature 567 (7748), pp. 309-310. https://doi.org/10.1038/d41586-019-00872-w.

Douglas, K. M. and Sutton, R. M. (2015). 'Climate change: Why the conspiracy theories are dangerous'. Bulletin of the Atomic Scientists 71 (2), pp. 98-106. https://doi.org/10.1177/0096340215571908.

Dudo, A., Brossard, D., Shanahan, J., Scheufele, D. A., Morgan, M. and Signorielli, N. (2010). 'Science on Television in the 21st Century'. Communication Research 38 (6), pp. 754-777. https: //doi .org/10.1177/0093650210384988.

European Union (March 2019). Special Eurobarometer 488Europeans' attitudes towards vaccination.

URL: https://data.europa.eu/data/datasets/s2223_91_2_488_eng.

Eurostat (2019). Reference Metadata in Euro SDMX Metadata Structure (ESMS). Bruxelles, Belgium: Eurostat.

URL: https://ec.europa.eu/eurostat/cache/metadata/en/urb_esms.htm.

Funk, C. and Kennedy, B. (27th August 2020). Public confidence in scientists has remained stable for decades. Update of the post originally published April 6, 2017. URL: https://www . pewresearch.org/fact-tank/2020/08/27/public-confide nce-in-scientists-has-remained-stable-for-decades/. 
Gavurová, B., Balloni, A., Tarhaničová, M. and Kováč, V. (2018). 'Information and Communication Technology in the Role of Information System of Healthcare Facility in the Slovak Republic'. Economies 6 (3), p. 47. https://doi.org/10.3390/economies6030047.

Hmielowski, J. D., Feldman, L., Myers, T. A., Leiserowitz, A. and Maibach, E. (2014). 'An attack on science? Media use, trust in scientists, and perceptions of global warming'. Public Understanding of Science 23 (7), pp. 866-883. https://doi.org/10.1177/0963662513480091.

ISCED (2013). International Standard Classification of Education - ISCED. Paris, France. URL: http://uis . unesco.org/en/topic/international-standard-classific ation-education-isced.

Kahan, D. M. (2017). 'Misconceptions, Misinformation, and the Logic of Identity-Protective Cognition'. SSRN Electronic Journal. https://doi.org/10.2139/ssrn.2973067.

Koivumäki, K., Koivumäki, T. and Karvonen, E. (2020). “'On Social Media Science Seems to Be More Human": Exploring Researchers as Digital Science Communicators'. Media and Communication 8 (2), pp. 425-439. https://doi.org/10.17645/mac.v8i2. 2812.

Lijphart, A. (1971). 'Comparative Politics and the Comparative Method'. American Political Science Review 65 (3), pp. 682-693. https://doi .org/10.2307/1955513.

Media Landscape (2020). Expert analysis of the state of media, European Journalism Centre, Dutch Ministry of Education, Culture and Science (OCW). URL: https://medialandscapes .org/country/italy.

Mrva, M. (2019). 'Fenomén všeobecnej dôvery na Slovensku vo svetle výskumu'. Sociológia a spoločnost' / Sociology and society 4 (1), pp. 30-47. https://doi.org/10.17846/ss.2019.4.1.30-47.

Pellegrini, G. and Rubin, A. (2020). 'Italy: The long and winding path of science communication'. In: Communicating Science: A Global Perspective. Ed. by T. Gascoigne, B. Schiele, J. Leach, M. Riedlinger, B. V. Lewenstein, L. Massarani and P. Broks. Canberra, Australia: ANU Press, pp. 469-494.

https://doi.org/10.22459/cs.2020. URL: http://press-files.anu.edu.au /downloads/press/n6484/pdf/ch20.pdf.

Prescott, T. and Urlacher, B. R. (2017). 'Case selection and the comparative method: introducing the case selector'. European Political Science 17 (3), pp. 422-436. https://doi.org/10.1057/s41304-017-0128-5.

Scheufele, D. A. and Krause, N. M. (2019). 'Science audiences, misinformation, and fake news'. Proceedings of the National Academy of Sciences 116 (16), pp. 7662-7669. https://doi.org/10.1073/pnas. 1805871115.

Seawright, J. and Gerring, J. (2008). 'Case Selection Techniques in Case Study Research'. Political Research Quarterly 61 (2), pp. 294-308. https://doi.org/10.1177/1065912907313077.

Vernon, J. L. (2017). 'Science in the Post-Truth Era'. American Scientists 105 (1), p. 2. URL: https://www . americanscientist.org/article/science-in-the-post-t ruth-era.

Wellcome Trust (18th June 2019). Wellcome Global Monitor 2018: How does the world feel about science and health. London, U.K.

URL: https://wellcome.ac.uk/reports/wellcome-global-monitor/2018. 
Sonia Brondi, $\mathrm{PhD}$, is an assistant professor in Social Psychology at the Department of Philosophy, Sociology, Education and Applied Psychology, University of Padua, Italy. Her main research interests include the study of social representations, collective memory and identity processes, applied to environmental, health and techno-scientific issues, as well as their mutual relationships with public participation. E-mail: sonia.brondi@unipd.it.

Giuseppe Pellegrini, PhD, teaches Innovation, Technology and Society at the University of Trento, Italy. His main research interests are related to the study of science, technology and society issues. In this area of investigation, he has devoted specific attention to public engagement and public communication. He is the president of Observa Science in Society. E-mail: pellegrini@observanet.it.

Peter Guráň, PhD, is a sociologist on human rights issues in Slovakia, where he is vice-chair of the National Committee on Children and Youth. As a former member of the UN Committee on the Rights of the Child (2009-2017), he was involved in the preparation of the 3rd CRC Optional Protocol on communication procedures and was a member of the first working group for its implementation. He actually teaches Sociology and Human Rights at the Trnava University, Slovakia. E-mail: guranpeter11@gmail.com.

Martin Fero, PhD, senior lecturer, researcher and sociologist at the Department of Sociology, Trnava University, Slovakia, and at the Institute of Humanities of the Slovak University of Technology, focused on the sociology of organization and labour, social media, the methodology of quantitative research and data analysis. Member of the Committee of the Slovak Sociological Association by the Slovak Academy of Sciences and chairman of the Department of Sociology of Organization and Labour of the Slovak Sociological Association by the Slovak Academy of Sciences. E-mail: feromartin@gmail.com.

Andrea Rubin, PhD, teaches Social Science Theory at the University of Bergamo, Italy. In the area of science and technology studies, his main research interests are public perception and public communication of science and public engagement. He is a science journalist and co-edited (with Giuseppe Pellegrini) the Yearbook on Science in Society 2020. E-mail: andrea.rubin@guest.unibg.it.

\section{How to cite}

Brondi, S., Pellegrini, G., Guráň, P., Fero, M. and Rubin, A. (2021). 'Dimensions of trust in different forms of science communication: the role of information sources and channels used to acquire science knowledge'. JCOM 20 (03), A08. https://doi.org/10.22323/2.20030208. 